\title{
Endoscopic negative pressure therapy as stand-alone treatment for perforated duodenal diverticulum: presentation of two
}

\section{cases}

\author{
Dörte Wichmann ${ }^{1 *}$ D, Kai Tobias Jansen ${ }^{1}$, Flurina Onken ${ }^{1}$, Dietmar Stüker ${ }^{1}$, Emanuel Zerabruck², \\ Christoph R. Werner ${ }^{3}$, Can Yurttas ${ }^{1}$, Karolin Thiel ${ }^{1}$, Alfred Königsrainer ${ }^{1}$ and Markus Quante ${ }^{1}$
}

\begin{abstract}
Background: Endoscopic negative pressure therapy is a novel and successful treatment method for a variety of gastrointestinal leaks. This therapy mode has been frequently described for rectal and esophageal leakages. Duodenal diverticular perforations are rare but life-threatening events. The early diagnosis of duodenal diverticular perforation is often complicated by inconclusive symptoms. This is the first report about endoscopic negative pressure therapy in patients with perforated duodenal diverticula.

Case presentation: We present two cases of duodenal diverticula perforations treated with endoscopic negative pressure therapy as stand-alone treatment. Start of symptoms varied from one to three days before hospital admission. Early sectional imaging led to the diagnosis of duodenal diverticular perforation. Both patients were treated with endoluminal endoscopic negative pressure therapy with simultaneous feeding option. Three respective changes of the suction device were performed. Both patients were treated with antibiotics and antimycotics during their hospital stay and be discharged from hospital after 20 days.

Conclusions: This is the first description of successful stand-alone treatment by endoscopic negative pressure therapy in two patients with perforated duodenal diverticulum. We thus strongly recommend to attempt interventional therapy with endoluminal endoscopic negative pressure therapy in patients with duodenal diverticular perforations upfront to surgery.
\end{abstract}

Keywords: Duodenal diverticulum perforation, Endoscopic negative pressure therapy, Endoscopic vacuum therapy, Spontaneous duodenal perforation

\section{Background}

Duodenal diverticula are present in $22 \%$ of the population [1]. A very rare but life-threatening complication of duodenal diverticula is possible perforation, which is associated with a mortality rate of up to $20 \%$ [2-4]. The

*Correspondence: doerte.wichmann@med.uni-tuebingen.de

1 Department of General, Visceral and Transplantation Surgery, University

Hospital of Tübingen, Hoppe-Seyler-Str. 3, 72076 Tübingen, Germany

Full list of author information is available at the end of the article clinical symptoms of a duodenal diverticula perforation (DDP) are often non-specific [5-7]. Early CT diagnosis represents the gold standard for detecting the localization of the perforation and further therapy planning [8]. Corresponding radiological findings may include duodenal wall thickening, depiction of the diverticulum, fluid and air collections, and retroperitoneal abscesses. In most cases, spontaneous DDP are localized at juxtapapillary position $[7,9]$. 
Compared with iatrogenic or postoperative duodenal leakage, spontaneous DDP are very rare [3]. According to the hitherto available literature, the majority of patients suffering from DDP is undergoing surgical therapy. Of note, there are only a few case reports about successful conservative therapy of this condition [7, 10-12].

Endoscopic negative pressure therapy (ENPT) is an effective treatment strategy for various defects of the gastrointestinal tract [13]. The functional principle is based on an open-pore suction device (OPSD), like an openpore polyurethan sponge, which is placed around a perforated drainage tube, for instance a nasogastric tube. This drainage tube is connected to a vacuum source. An electric vacuum pump with pressure monitoring is recommended for ENPT in the upper GI [14]. In Fig. 1a graphical flow chart of procedures and materials is presented. The OPSD could be placed endoluminal or intracavitary. It is a relatively new therapeutic method, which was introduced in 2000 and rapidly spread due to good clinical results. ENPT improves local perfusion, resolution of interstitial wound edema, removal of fluids, and debridement of the wound base. ENPT is also named EndoVac-therapy or endoscopic vacuum therapy (EVAC or EVT). Different open-pore materials are available for the ENPT. Often, the endoscopist prepares the appropriate OPSD for ENPT from a tube and an open-pored material himself. In the article "Tips and tricks for endoscopic negative pressure therapy" G. Loske introduced different open-pore elements based on the open-pore film $\left(\mathrm{CNP}^{\circledR}\right.$-film $=$ Suprasorb $\mathrm{CNP}^{\circledR}$ Drainage Film; Lohmann \& Rauscher International GmbH \& Co.KG, Rengsdorf, Germany) and polyurethane sponge [14]. The use of feeding tubes for ENPT in endoluminal position can ensure patients' enteralization for the duration of therapy [15].

Here, we present the first report about successful ENPT as stand-alone treatment for DDP in two patients.

\section{Case presentation}

We report about two female patients with spontaneous DDP. Demographic details, medical history and symptoms are listed in Table 1. In Fig. 2, CT-scan at time of hospital admission of both patients is shown. At the first gastroscopy in both patients an acute duodenitis with pus in pars ascendens duodeni was founded. The perforations were not visualized in both cases.

After imaging, both patients underwent initial endoscopic examination by gastroscopies under sedation and

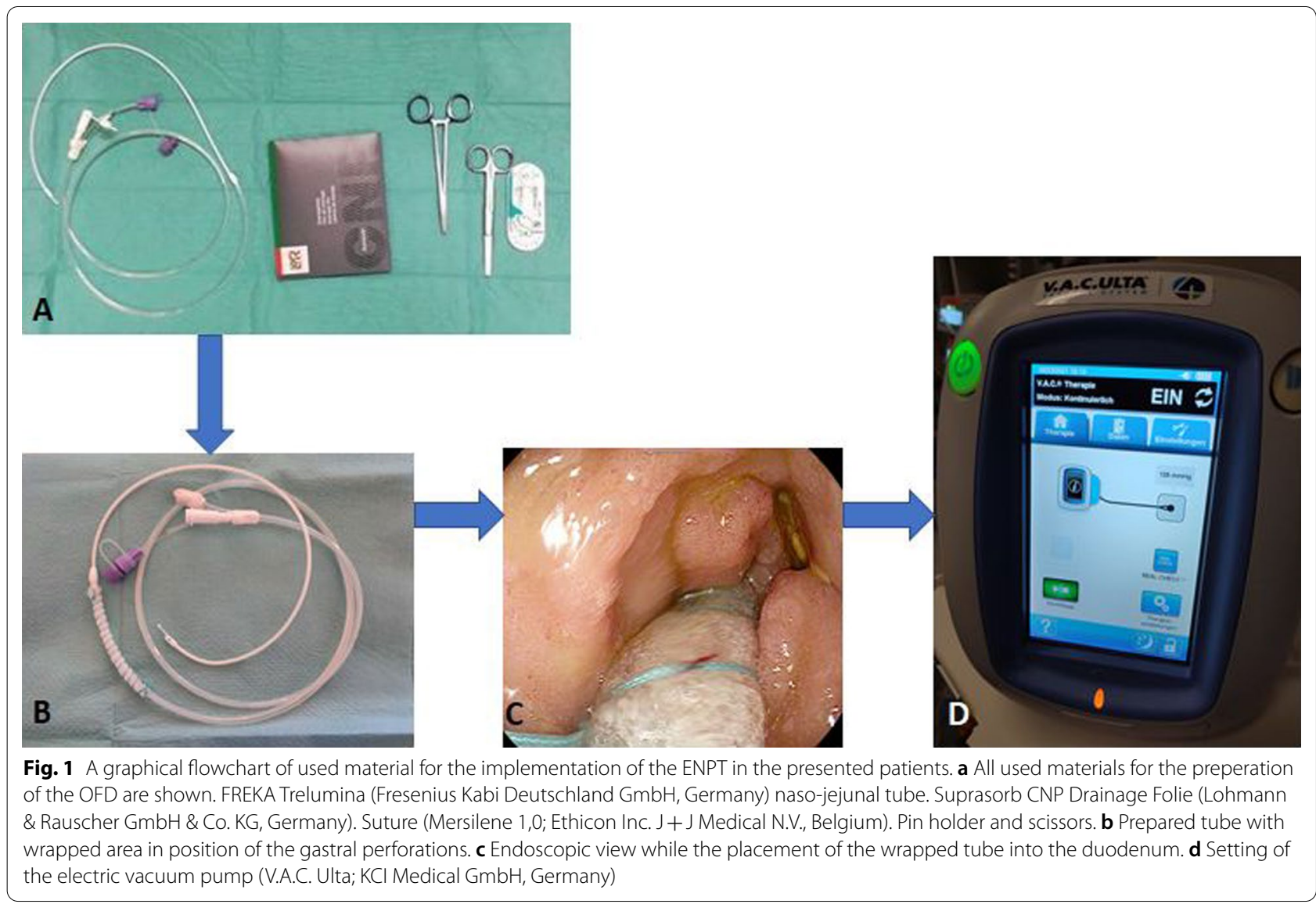


Table 1 Patients characteristics

\begin{tabular}{|c|c|c|}
\hline & Patient \#1 & Patient \#2 \\
\hline Age & 69 & 82 \\
\hline Pre-existing conditions & None & None \\
\hline $\begin{array}{l}\text { Delay between start of symptoms and } \\
\text { hospital admission }\end{array}$ & 4 & 1 \\
\hline \multirow[t]{3}{*}{ Laboratory findings } & WBC $13,300 / \mu l$ & 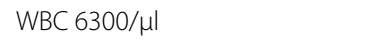 \\
\hline & CRP $30.96 \mathrm{mg} / \mathrm{dl}$ & CRP $0.25 \mathrm{mg} / \mathrm{dl}$ \\
\hline & Serum bilirubin 0.6 mg/dl & Serum bilirubin $1.5 \mathrm{mg} / \mathrm{dl}$ \\
\hline Findings in primary sectional imaging & $\begin{array}{l}\text { Hollow organ perforation with free retroperitoneal air. Air and fluid } \\
\text { retention along the dorsal circumferential pars II duodeni }\end{array}$ & $\begin{array}{l}\text { Perforated duodenal diverticulum } \\
\text { with compression of the papillary } \\
\text { region }\end{array}$ \\
\hline
\end{tabular}
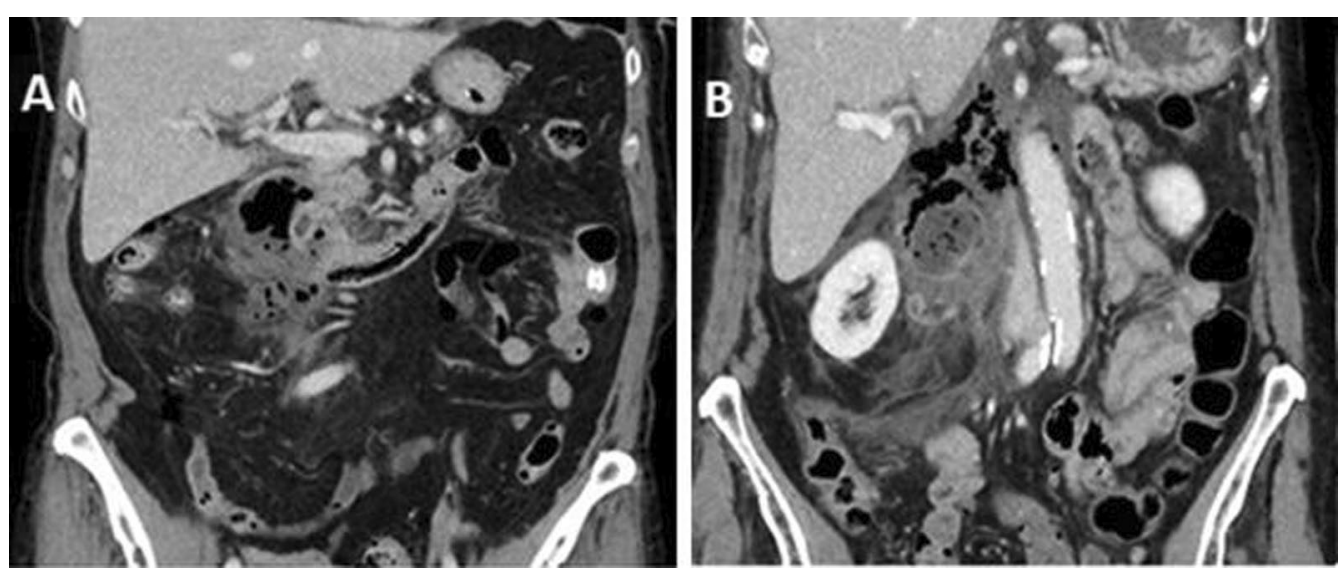

Fig. 2 Primary CT-scan of Patient \#1 (a) and Patient \#2 (b)

were each given a feeding tube with endoluminal OPSD. Reason for first-line endoscopic treatment approach was the desire to avoid laparotomy with opening of retroperitoneum during the acute inflammation. In parallel, antibiotic and antifungal treatment was promptly established.

We created OPSD using $3 \mathrm{ml}$ enteral feeding tubes (Freka Trelumina ${ }^{\circledR}$, Fresenius Kabi Deutschland GmbH, Bad Homburg, Germany) and a cut piece of $\mathrm{CNP}^{\circledR}$ film of $2 \times 10 \mathrm{~cm}\left(\mathrm{CNP}^{\circledR}{ }^{\circledR}\right.$ film $=$ Suprasorb $\mathrm{CNP}^{\circledR}$ Drainage Film; Lohmann \& Rauscher International GmbH \& Co.KG, Rengsdorf, Germany). The prepared tube was guide wired placed deep duondenal. The wrapped gastral parts of the tubes were placed into the duodenum. Endoscopic control of the right position was realized.

The gastral tubes were connected to an electric vacuum pump with pressure monitoring (KCI V.A.C. ${ }^{\circledR}$ Ultra Therapy Unit, KCI USA Inc., San Antonio, Texas, United States), according to the description of a fashioned device using a two lumen tube as already described [15]. The predetermined vacuum was $125 \mathrm{mmHg}$ according to the usually used negative pressure for ENPT in the gastrointestinal tract [14].

A diagnostic re-endoscopy was performed once a week. In both patients one additional re-endoscopy for device dislocation was performed. If a persistent perforation was suspected a new OPSD according to the described device was placed into the duodenum. In each case, three respective changes of the system were performed with a total therapy duration of 16 and 17 days. Endoscopic examinations were performed under sedation. Treatment relevant aspects are listed in Table 2.

Antibiotic and antifungal therapy was terminated after five days. In both patients, three follow-up CT scans were performed to monitor the therapy. Fortunately, both patients recovered quickly, were mobile, and were able to drink sips. Patient \#2 also underwent a final diverticulography to ensure that the perforation was closed (Fig. 3). After removal of the OPSD both patients were further monitored in the hospital setting for three and four days, respectively. The patients were discharged when food 
Table 2 Treatment relevant aspects

\begin{tabular}{|c|c|c|}
\hline & Patient \#1 & Patient \#2 \\
\hline Antibiotic Management & 5 days cefotaxime, metronidazole and fluconazol & 5 days piperacillin and tazobactam and fluconazol \\
\hline Endoscopic Management & $\begin{array}{l}\text { OPSD using } 3 \mathrm{ml} \text { feeding tube, end of therapy after good } \\
\text { progress in CT-imaging }\end{array}$ & $\begin{array}{l}\text { OPSD using } 3 \mathrm{ml} \text { feeding tube, concluding diverticulog- } \\
\text { raphy to exclude a persistent perforation }\end{array}$ \\
\hline Number of changes of the OPSD & 4 & 4 \\
\hline Number of progress CT & 3 & 3 \\
\hline Length of hospital stay & 20 days & 20 days \\
\hline Adverse events & One accidental dislocation of the tube & One accidental dislocation of the tube \\
\hline $\begin{array}{l}\text { Follow-up telephone survey } \\
6 \text { weeks after hospital discharge }\end{array}$ & Yes, well-being, supplies itself completely independently & $\begin{array}{l}\text { Yes, well-being, supplies itself completely independently, } \\
\text { occasional vertigo }\end{array}$ \\
\hline
\end{tabular}
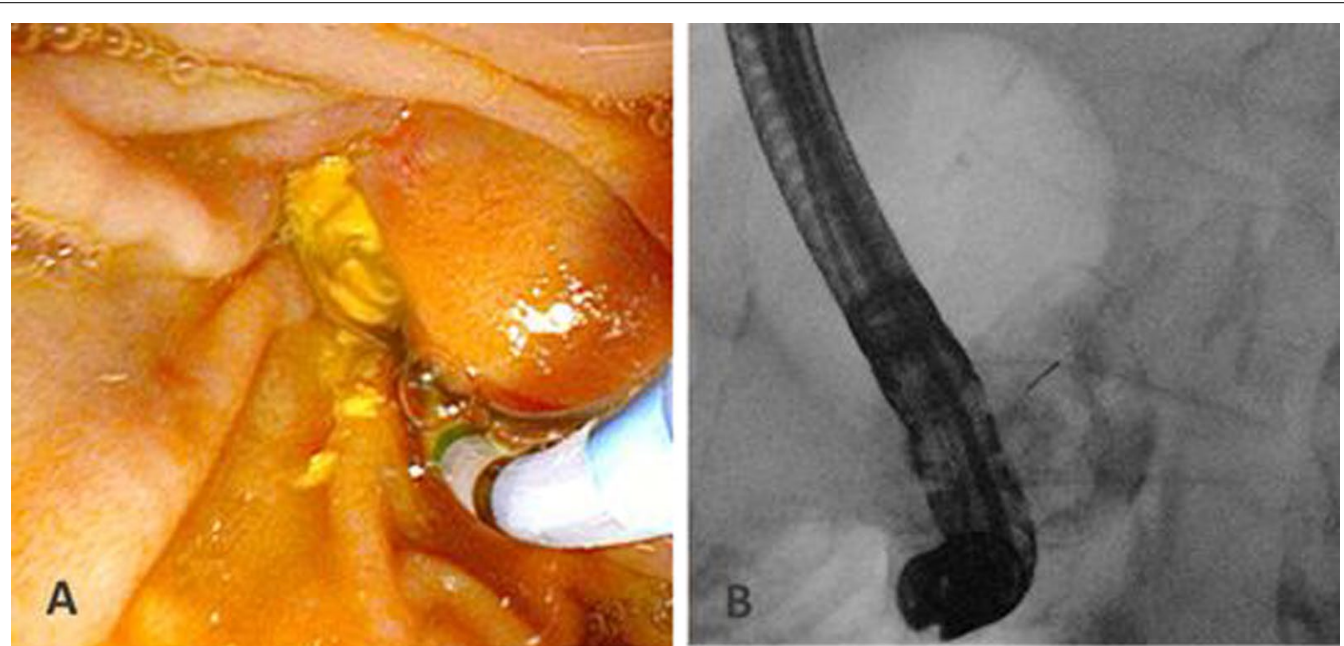

Fig. 3 Endoscopic image (a) at the time of the diverticulography (b)
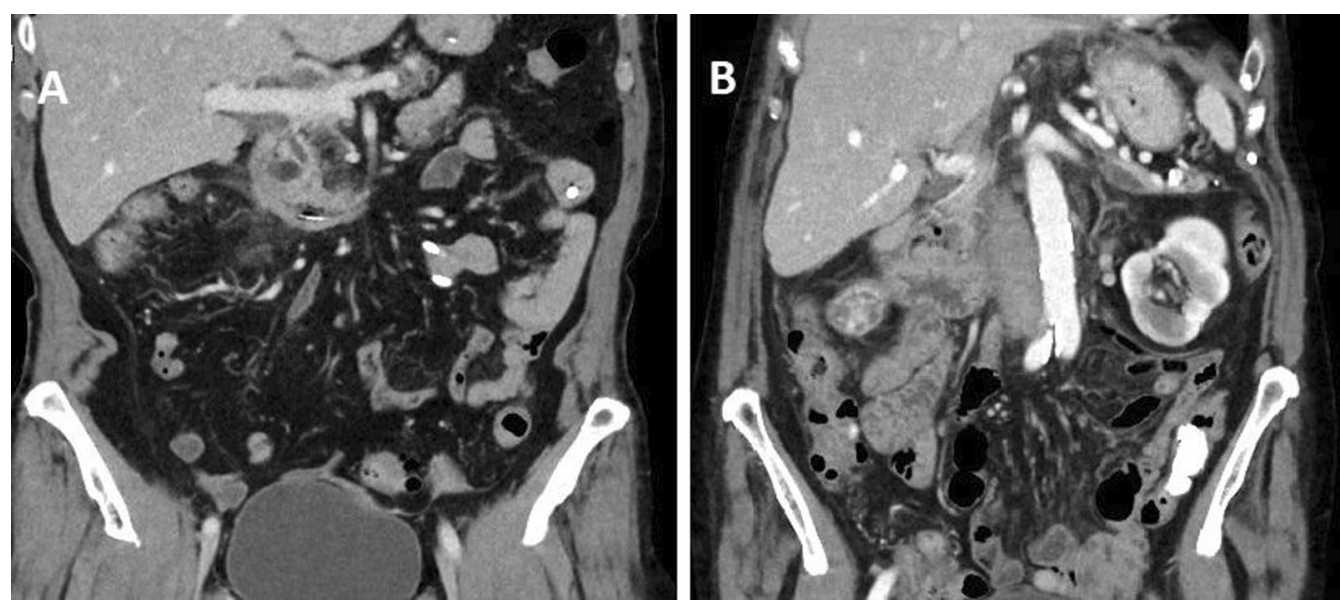

Fig. 4 Last CT-scan prior discharge of Patient \#1 (a) and Patient \#2 (b)

intake and digestion were well established. In Fig. 4 the CT-scan prior discharge is shown in contrast to Fig. 2.
Six weeks after discharge a telephone interview was performed with both patients. They reported on good clinical conditions while still feeling physically weak. No 
re-admissions to hospital or further episodes of abdominal pain had occurred. Both patients were grateful that they could be treated without surgery.

\section{Discussion and conclusions}

Spontaneous duodenal diverticular perforations are rare but life-threatening events [6]. A literature search for the term "duodenal diverticular perforation" was performed in PubMed. We screened all articles published since 1990 and found a total of 19 case reports and case series describing the treatment of 73 patients (Additional file 1: Table S1). Most common therapy in DDP was surgical in 62 of 73 cases (84.93\%). Here, various described operative modii have been reported from open duodenal resection [3] to laparoscopic diverticulectomies [16]. Conservative treatment including nil per ore and antibiotic therapy was described as successful in 11 cases. Overall mortality rate in patients suffering from DDP reported was $10.34 \%$. However, these results may be positively biased since case reports are mainly written in cases that had a positive outcome. There are relevant differences between DDP, and duodenal perforations caused by other etiologies:

1. The absence of a previous trauma or gastrointestinal intervention, which may indicate the presence of perforation in the upper GI-tract. Early diagnosis of a DDP is complicated.

2. The duodenal blood circulation is not affected in cases of DDP compared to anastomotic insufficiencies.

3. The typical localization of the perforation is retroperitoneal starting from pars ascendens duodeni.

ENPT in intracavitary and endoluminal position is increasingly used due to its excellent results in different leakages of the upper and lower gastrointestinal tract [13, 17]. ENPT in duodenal position has been described by Loske, Glatz and Yoo [18-20]. These authors described the use of ENPT in cases of postoperative or iatrogenic leakages of the duodenum.

To the best of our knowledge, we are the first to report on successful ENPT in patients with DDP. Especially for retroperitoneal perforations, this therapy mode allows good drainage of possible abscesses in addition to fluid removal. Of critical importance for the patients, enteralization was ensured during the time of ENPT. Based on the reported results, we strongly recommend to attempt primary endoscopic therapy using ENPT for DDP.
Abbreviations

CRP: C-reactive protein; DDP: Duodenal diverticular perforation; ENPT: Endoscopic negative pressure therapy; Gl: Gastrointestinal; OPSD: Open-pore suction device; WBC: White blood cells.

\section{Supplementary Information}

The online version contains supplementary material available at https://doi. org/10.1186/s12876-021-02018-7.

Additional file 1. Analysis of existing literature.

Acknowledgements

Not applicable.

Authors' contributions

Conception: DW, KTJ, FO. Design: DW, KTJ, FO, AK, MQ. Interpretation of data: DW, KTJ, FO, MQ. Revision: DW, KTJ, FO, DS, EZ, CRW, CY, KT, AK, MQ. Approved the submitted version: DW, KTJ, FO, DS, EZ, CRW, CY, KT, AK, MQ. All authors have read and approved the manuscript.

\section{Funding}

Open Access funding enabled and organized by Projekt DEAL. Publication fees are covered by the open access publication fund at the University of Tübingen.

\section{Availability of data and materials}

The datasets used and/or analyzed during the current study are available from the corresponding author on reasonable request.

\section{Declarations}

Ethics approval and consent to participate

This study was approved by the Institutional Review Board of the University of Tübingen, Germany (Number 241/2021BO2). Patients gave their informed consent in writing.

\section{Consent for publication}

Written informed consent was obtained from the patient for publication of this case report and any accompanying images. A copy of the written consent is available for review by the Editor of this journal.

\section{Competing interests}

The authors declare that they have no competing interests.

\section{Author details}

${ }^{1}$ Department of General, Visceral and Transplantation Surgery, University Hospital of Tübingen, Hoppe-Seyler-Str. 3, 72076 Tübingen, Germany. ${ }^{2}$ Interdisciplinary Endoscopic Unit, University Hospital of Tübingen, Hoppe-Seyler-Str. 6, 72076 Tübingen, Germany. ${ }^{3}$ Department of Internal Medicine I, Gastroenterology, Hepatology, Gastrointestinal Oncology, Infectiology and Geriatrics, University Hospital of Tübingen, Otfried-Müller-Str. 10, 72076 Tübingen, Germany.

Received: 21 May 2021 Accepted: 8 November 2021

Published online: 21 November 2021

\section{References}

1. Ackermann W. Diverticula and variations of the duodenum. Ann Surg. 1943:117(3):403-13.

2. Haboubi D, Thapar A, Bhan C, Oshowo A. Perforated duodenal diverticulae: importance for the surgeon and gastroenterologist. BMJ Case Rep. 2014;2014:bcr2014205859. 
3. Oukachbi N, Brouzes S. Management of complicated duodenal diverticula. J Visc Surg. 2013;150(3):173-9.

4. Costa Simoes V, Santos B, Magalhaes S, Faria G, Sousa Silva D, Davide J. Perforated duodenal diverticulum: surgical treatment and literature review. Int J Surg Case Rep. 2014;5(8):547-50.

5. Dennesen PJ, Rijken J. Duodenal diverticulitis. Neth J Med. 1997;50(6):250-3.

6. Thorson CM, Paz Ruiz PS, Roeder RA, Sleeman D, Casillas VJ. The perforated duodenal diverticulum. Arch Surg. 2012:147(1):81-8.

7. Moysidis M, Paramythiotis D, Karakatsanis A, Amanatidou E, Psoma E, Mavropoulou X, et al. The challenging diagnosis and treatment of duodenal diverticulum perforation: a report of two cases. BMC Gastroenterol. 2020;20(1):5.

8. Ames JT, Federle MP, Pealer KM. Perforated duodenal diverticulum: clinical and imaging findings in eight patients. Abdom Imaging. 2009:34(2):135-9.

9. Lobo DN, Balfour TW, Iftikhar SY, Rowlands BJ. Periampullary diverticula and pancreaticobiliary disease. Br J Surg. 1999:86(5):588-97.

10. Kim KH, Park SH. Conservative treatment of duodenal diverticulitis perforation: a case report and literature review. Open Access Emerg Med. 2018;10:101-4.

11. Martinez-Cecilia D, Arjona-Sanchez A, Gomez-Alvarez M, Torres-Tordera E, Luque-Molina A, Valenti-Azcarate V, et al. Conservative management of perforated duodenal diverticulum: a case report and review of the literature. World J Gastroenterol. 2008;14(12):1949-51.

12. Sahned J, Hung Fong S, Mohammed Saeed D, Misra S, Park IS. Duodenal diverticulitis: to operate or not to operate? Cureus. 2019;11(11):e6236.

13. de Moura DTH, de Moura B, Manfredi MA, Hathorn KE, Bazarbashi AN, Ribeiro IB, et al. Role of endoscopic vacuum therapy in the management of gastrointestinal transmural defects. World J Gastrointest Endosc. 2019;1 1(5):329-44.

14. Loske G, Muller CT. Tips and tricks for endoscopic negative pressure therapy. Chirurg. 2019;90(Suppl 1):7-14.

15. Archid R, Bazerbachi F, Thomas MC, Konigsrainer A, Wichmann D. Endoscopic negative pressure therapy for upper gastrointestinal leaks: description of a fashioned device allowing simultaneous enteral feeding. VideoGIE. 2021;6(2):58-61.

16. Yeh TC. Laparoscopic resection of perforated duodenal diverticulum - a case report and literature review. Int J Surg Case Rep. 2016;28:204-10.

17. Loske G. Endoscopic negative pressure therapy of the upper gastrointestinal tract. Chirurg. 2019;90(Suppl 1):1-6.

18. Loske G, Liedke M, Schloricke E, Herrmann T, Rucktaeschel F. Endoscopic negative-pressure therapy for duodenal leakage using new open-pore film and polyurethane foam drains with the pull-through technique. Endoscopy. 2017;49(12):E300-2.

19. Yoo T, Hou LA, Reicher S, Chen KT, Eysselein VE. Successful repair of duodenal perforation with endoscopic vacuum therapy. Gastrointest Endosc. 2018;87(5):1363-4.

20. Glatz T, Fischer A, Hoeppner J, Thimme R, Walker C, Richter-Schrag HJ. Vacuum sponge therapy using the pull-through technique via a percutaneous endoscopic gastrostomy to treat iatrogenic duodenal perforation. Endoscopy. 2015;47(Suppl 1):E567-8.

\section{Publisher's Note}

Springer Nature remains neutral with regard to jurisdictional claims in published maps and institutional affiliations.
Ready to submit your research? Choose BMC and benefit from:

- fast, convenient online submission

- thorough peer review by experienced researchers in your field

- rapid publication on acceptance

- support for research data, including large and complex data types

- gold Open Access which fosters wider collaboration and increased citations

- maximum visibility for your research: over $100 \mathrm{M}$ website views per year

At BMC, research is always in progress.

Learn more biomedcentral.com/submissions 